\title{
ADDICTION LIVES: INGEBORG ROSSOW
}

\author{
[PHOTO]
}

Photo credit: SIRUS

Berridge, Virginia*

Centre for History in Public Health,London School of Hygiene and Tropical Medicine 15-17 Tavistock Place London WC1H 9SH

Addiction Lives records the views and personal experiences of people who have especially contributed to the evolution of ideas in addiction science. To suggest an interviewee, send a statement of up to 50 words summarising the person's exceptional contribution to the field to the Addiction Lives Editor: Prof Virginia Berridge, Centre for History in Public Health, London School of Hygiene and Tropical Medicine, 15-17 Tavistock Place, London WC1 H 9SH, tel +44 (0)207927 2269, email Virqinia.Berridge@lshtm.ac.uk.

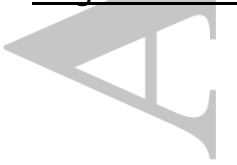

\section{INTERVIEW SUMMARY BY VIRGINIA BERRIDGE}

Ingeborg Rossow is a distinguished epidemiologist. She was born in Oslo, Norway and is still based there. Her career path was quite different from her early career ideas. She thought of being a glass artist or a social worker and worked as a nurse in a psychiatric hospital. She graduated in criminology because it was the only subject available in the autumn after she returned from abroad. It was a radical period in Norway in the mid-1970s and Marxism/Leninism was strong at the Institute of Criminology, where crime was seen as part of social structure with a social science approach to the study of crime.

She then moved into dentistry, as a way of doing something active through clinical work rather than sitting behind a desk. She enjoyed helping patients and meeting all sorts of people and doing dental research was also very interesting. There were no positions in the Dental Faculty in Oslo so, on the advice of a friend, she applied for a postdoctoral position on alcohol and suicide at the National Institute for Drug and Alcohol Research in Oslo. Her training in epidemiology helped in her appointment to the post. The project was led by Ole-Jørgen Skog, whom she sees as an 'intellectual giant', a strong personality who could be harsh with people but who was also warm hearted with a wide range of interests and who was a great influence on her.

The alcohol and suicide project included an international part involving alcohol researchers from various drinking cultures. The researchers looked at whether the association between alcohol consumption and suicide rates varied across different drinking cultures. There was a huge variation in the estimated magnitude of the association, with the strongest association in countries such as Norway, Sweden or Finland where heavy episodic drinking is a typical feature of the drinking culture. This approach was subsequently used in other studies, including a European Comparative Alcohol project led by Thor Norström. The knowledge that there is a causal relationship between the amount of alcohol drunk in a society and the amount of suicide leads to the conclusion that policies which reduce total consumption will impact on these outcomes.

This article has been accepted for publication and undergone full peer review but has not been through the copyediting, typesetting, pagination and proofreading process which may lead to differences between this version and the Version of Record. Please cite this article as doi: $10.1111 /$ add. 14274

This article is protected by copyright. All rights reserved. 
Ingeborg Rossow's research led to participation in the alcohol policy book, Alcohol: No Ordinary Commodity, and the drug policy book, Drug Policy and the Public Good, both of which stemmed from a tradition going back into the 1970s. Both the later books had Tom Babor at the steering wheel. Robin Room was a strong influence on her. She is now part of the team working on a similar book on gambling and public policy. She has studied community level prevention. The message from research is that price and availability are very strong measures to keep levels of consumption and harm at a relatively low level. What actually might be done at the local level is more varied-restriction of outlets; of on premises licences; of concentration; or of total numbers of premises, and it is unclear which to give priority to. Research on this area led to an unpleasant episode in her career. She had published an article showing that restrictions on premises trading hours led to lowered levels of violence and this attracted enormous media attention in Norway. The hospitality industry questioned her integrity but in the end this blew over. Probably such reactions are inevitable.

Norwegian drug and alcohol research in the early 1990s was based in a research institute which was almost fully funded by government money, a rare position which lasted until quite recently. There was a strong tradition of Nordic cooperation and there is still a Nordic journal on alcohol and drugs. Two years ago this institute was merged with a public health institute and times are harsher, so there is greater dependence on obtaining external funding. The relationship with government could be difficult and in 1992 the Institute had its funding cut by half after a researcher promoted a liberal view on cannabis in the media. Skog, the Director, resigned and there was support from colleagues round the world. In the end the funding was restored.

In the future she would like to see research broaden from the few relatively rich countries which have dominated and the building of broader international cooperation including low and middle income countries (LAMI).To achieve this, the international research community can help by coming up with constructive reviews which help such researchers to publish and increase capacity.

\section{LINK TO FULL INTERVIEW, CONDUCTED BY KEITH HUMPHREYS, ON THE SOCIETY FOR THE STUDY OF ADDICTION WEBSITE:}

https://www.addiction-ssa.org/knowledge-hub/topic/addiction-lives

\section{ANNOTATED BIBLIOGRAPHY}

Rossow I. Suicide, alcohol, and divorce; aspects of gender and family integration. Addiction 1993; 88: 1659-1665.

This study represents my debut in several respects: as researcher in the alcohol and drug area, as analyst of aggregate level data, as contributor to the journal ADDICTION, and as participant in an international research project. The study shows that population drinking impacted on suicide rates in Norway. This study was part of an international collaboration project on alcohol and suicide (IPAS) led by Ole-Jørgen Skog. Other studies in this international project reported fairly similar findings, but the strength of the association between population drinking and suicide rates varied considerably between countries. In sum, these studies lent early support to the idea that the impact of total alcohol consumption on suicide rates is stronger in countries where drinking to intoxication is a more prominent feature of the drinking culture.

Rossow, I. Alcohol and homicide, a cross-cultural comparison of the relationship in 14 European countries. Addiction, 2001; 96, Supplement S77-S92.

This study was part of the European Comparative Alcohol Studies (ECAS) project, led by Thor

This article is protected by copyright. All rights reserved. 
Norström. Much in line with the observations in the IPAS project of cross-cultural variation in the alcohol-suicide association, this study found that the impact of total consumption on homicide rates varied across European countries, being stronger in Northern Europe where intoxication drinking occurs more frequently. Similar comparative projects to ECAS were undertaken later on, adding to our understanding of the impact of population drinking on public health and the importance of drinking patterns in this respect.

Rossow I. Alcohol related violence; - the impact of drinking pattern and drinking context. Addiction 1996; 91: 1641-1651.

This study was first presented at a Kettil Bruun Society Thematic Meeting on drinking patterns in 1995. At that time, the importance of drinking patterns in explaining health and social consequences of alcohol use was still 'an emerging paradigm'. This survey-based study shows that, having controlled for volume of drinking, drinking to intoxication adds to the risk of being involved in alcohol-related violence, as perpetrator as well as victim.

Rossow, I., Pernanen, K. \& Rehm, J. Accidents, suicides and violence. In: Klingeman, H. \& Gmel, G. (Eds) Mapping social consequences of alcohol consumption. WHO publication monograph, Kluwer Academic Press, 2001.

This book section reviews the literature on alcohol consumption and social consequences in three areas. The book is a result of a collaborative study with the participation of an international group of alcohol researchers under the leadership of WHO-EURO, attempting to provide a comprehensive overview of social consequences of alcohol consumption. Despite a wide recognition of alcohol as an important risk factor for various social harms, research on consequences of drinking is still mainly in the health domain.

Room, R. \& Rossow, I. Share of violence attributable to drinking. Journal of Substance Use, 2001; 6, 218-228.

I've had the privilege and pleasure of working with Robin Room in a number of projects over the years. In this 'think piece' we review literature on the alcohol-violence association, both at the individual and at the aggregate level, and discuss the variation in alcohol-attributable fraction of violence across various drinking cultures.

Rossow, I. \& Lauritzen, G. Shattered childhood - a key issue in suicidal behaviour among drug addicts? Addiction, 2001; 96, 227-240.

As an epidemiologist, I find it very stimulating to collaborate with colleagues who have longtime clinical experience in this field, as was the case in this study. The drug users reported frequent suicide attempts and suicidal ideation, and these behaviours were clearly associated with various adverse childhood experiences. Virtually all of the study participants reported one or several such experiences. References to the findings regarding 'shattered childhood' are later made also with respect to the self-medication hypothesis.

Mäkelä, P., Rossow, I., Tryggvesson, K. Who drinks more and less when policies change? In: Room, R. (Ed) The effects of Nordic alcohol policies. What happens to drinking and harm when alcohol controls change? NAD Publication \# 42 Helsinki: Nordic Council for Alcohol and Drug Research, 2002, pp. 1770.

This book resulted from a Nordic collaborative project led by Robin Room. The chapter reviews a fairly large literature, mainly in the Nordic languages, on outcomes of changes in alcohol policy measures and possible differential outcomes by sociodemographic groups and 
drinking status. Contrary to what is often claimed in public debates on alcohol policy, this review showed that control policies tend to have more impact on heavy drinkers than other drinkers.

Babor, T., Caetano, R., Casswell, S., Edwards, G., Giesbrecht, N., Graham, K., Grube, J., Gruenewald, P., Hill, L., Holder, H., Homel, R., Österberg, E., Rehm, J., Room, R., Rossow, I. (2003) Alcohol: No Ordinary Commodity - Research and Public Policy. Oxford: Oxford University Press.

This book follows in the footsteps of two previous co-authored books on alcohol policy. The collaborative process was initiated by Griffith Edwards, who was Editor of ADDICTION at that time, and Cees Goos at WHO-EURO. The book reviews the world literature on the science base for alcohol policy, and it is frequently cited in the scientific literature. In 2004 the book won first prize in the public health category in the British Medical Association's book awards and was ranked in the top three when the second edition was published in 2010.

Rossow I. Inferences of associations and implications for prevention: the case of early drinking onset. In: Elster J, Gjelsvik O, Hylland A, Moene K. (Eds) Understanding choice and explaining behaviour. Essays in honour of Ole-Jørgen Skog. Oslo: UniPub, 2006, pp. 259-272.

I was fortunate and grateful to have Ole-Jørgen Skog as mentor, colleague and friend. This essay is a critical review of the literature on associations between early drinking onset and later drinking behaviour, both with regard to causal inferences from observed co-variations and with regard to implications of such associations.

Norström, T., Miller, T., Holder, H., Österberg, E., Ramstedt, M., Rossow, I., Stockwell, T. Potential consequences of replacing a retail alcohol monopoly with a private license system: results from Sweden. Addiction; 2010; 105: 2113-2119.

This paper summarizes a report that resulted from an international collaboration attempting to project the potential consequences in the event that the Swedish monopoly on retail alcohol sales was abolished. The projected consequences were substantial, and such projections are likely important in alcohol policy making processes.

Babor, T., Caulkins, J., Edwards, G., Fischer, B., Foxcroft, D.R., Humphreys, K., Obot, I., E., Rehm, J., Reuter, P., Room, R., Rossow, I., Strang, J. Drug Policy and the Public Good, Oxford: Oxford University Press, 2010.

Griffith Edwards convened a group of career scientists to summarize the science base relevant to national and international drug policy. The scope of the book, the structure, and the process of writing the book resembled that of Alcohol: No Ordinary Commodity. The book found mixed evidence for current policy options in the areas of demand reduction and supply control, yet current drug policy in most societies takes little or limited account of this research. A second edition will be published in 2018.

Rossow, I., Moan, I.S. Parental intoxication and adolescent suicidal behavior. Archives of Suicide Research, 2012; 16: 73-84.

Over the past decade, there has been a growing interest in alcohol's harm to others. In this study we found elevated risk of suicidal behaviour among adolescents frequently exposed to parental intoxication. The article was rewarded 'Best paper of the year' in the journal.

Rossow, I. \& Norström, T. The impact of small changes in bar closing hours on violence. The Norwegian experience from 18 cities. Addiction, 2012; 107: 530-537 (E-pub Nov 2011). 
This study shows that even small changes in bar closing hours impact on violence rates. Pending the findings and publication of this study, the Norwegian Government had postponed a decision on whether or not to restrict the maximum closing hours. Immediately after its publication, the paper was attacked by the hospitality industry and, a little later, the Norwegian Government decided against the proposed restriction.

Rossow, I. \& Bramness, J.G. The total sales of prescription drugs with an abuse potential predicts the number of excessive users: a national prescription database study. BMC Public Health, 2015; 15: 288.

Even under a prescription system controlling availability of pharmaceutical drugs, excessive use and abuse of prescribed drugs occur. In this national registry-based study, we found that drugs with abuse potential, such as sleep medication, tranquilizers and pain relievers, were used in excessive amounts by a relatively small fraction of users. However, their drug use accounted for about half of the total sales of these drugs in Norway.

Rossow, I., Hansen, M.B. Gambling and gambling policy in Norway - an exceptional case. Addiction, 2016; 111: 593-598.

This article gives an account of how gambling policy developed in Norway and how the policy restrictions in the 2000s represent an exception to a general trend of liberalization and increased gambling.

Rossow, I., Keating, P., Felix, L., McCambridge, J. Does parental drinking influence children's drinking? A systematic review of prospective cohort studies. Addiction, 2016; 111: 204-217.

Even though it is often stated or implied that parents' drinking influences that of their children, this study shows that there is no strong empirical evidence to support this assumption.

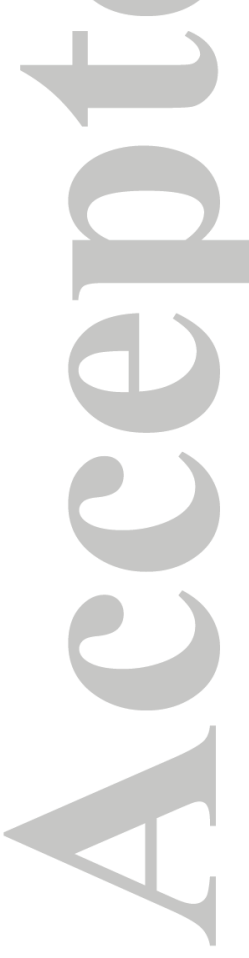

This article is protected by copyright. All rights reserved. 